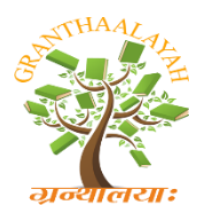

\author{
INTERNATIONAL JOURNAL OF RE
GRANTHAALAYAH \\ A knowledge Repository
}

Science

\title{
THE EFFECT OF NIMODIPINE ON CALCIUM INTRACELLULAR AND ROS EXPRESSION IN NEURON CULTURE CELL LINE SH-SY5Y INDUCE CHRONIC HIPERGL YCEMIA
}

\author{
Shahdevi Nandar Kurniawan ${ }^{*}$, Kandhisa ${ }^{1}$, Catur Arisetianto ${ }^{1}$, Nanik Setijowati ${ }^{2}$ \\ ${ }^{* 1}$ Neurology Department, Faculty of Medicine Brawijaya University, Malang, Indonesia \\ ${ }^{2}$ Public Health Department, Faculty of Medicine Brawijaya University, Malang, Indonesia
}

\begin{abstract}
Introduction: A frequent microvascular complication of diabetes mellitus were peripheral neuropathies with a prevalence of around $30-50 \%$. Generally, oxidative stress is the key to the pathological process that induces damage to peripheral nerves in sensory neurons thereby increasing the production of reactive oxygen species (ROS) and mitochondrial dysfunction which causes deregulation of calcium ion homeostasis and disrupted calcium signaling. Nimodipine is an L-type $\mathrm{Ca}^{2+}$ inhibitor that reactivates the ATPase pathway, has a neuroprotective effect and can improve the regulation of blood and nerve flow in restoring the adrenergic function of the vasa nervorum. Aim: The purpose of this study was to determine the effect of $0.5 \mu \mathrm{m}$ nimodipine on intracellular calcium and ROS expression in SH-SY5Y cell cultures induces chronic hyperglycemia.

Method: Normoglycemic glucose-induced cell culture of neurons $25 \mathrm{mM}, 50 \mathrm{mM}$ hyperglycemia for 6 days and then given nimodipine and without $0.5 \mu \mathrm{M}$ nimodipine.

Results: Based on the results of the One-Way ANOVA test, there was a significant difference $(\mathrm{p}<0.05)$ in intracellular calcium expression and ROS in cell cultures exposed to chronic hyperglycemia. Nimodipine $0.5 \mu \mathrm{M}$ significantly reduced intracellular calcium expression but did not reduce ROS expression. The Spearman rank correlation test $(r=0.5 ; p>0.05)$ given nimodipine $0.5 \mu \mathrm{M}$ therapy found a positive correlation, but not significant.

Conclusion: Based on this study it can be concluded that the administration of $0.5 \mu \mathrm{M}$ nimodipine can reduce intracellular calcium expression but has not been able to reduce ROS expression in $50 \mathrm{mM}$ glucose-induced cell cultures.

Keywords: Nimodipine; Diabetic Neuropathy; Calcium Intracellular; ROS; SH-SY5Y.

Cite This Article: Shahdevi Nandar Kurniawan, Kandhisa, Catur Arisetianto, and Nanik Setijowati. (2020). "THE EFFECT OF NIMODIPINE ON CALCIUM INTRACELLULAR AND ROS EXPRESSION IN NEURON CULTURE CELL LINE SH-SY5Y INDUCE CHRONIC HIPERGLYCEMIA." International Journal of Research - Granthaalayah, 8(2), 272-278. https://doi.org/10.29121/granthaalayah.v8.i2.2020.219.
\end{abstract}




\section{Introduction}

Diabetes mellitus is a chronic metabolic disorder due to the pancreas not producing enough the insulin or the body cannot use insulin produced effectively. Insulin is a hormone that regulates the balance of blood sugar levels, resulting in an increase in glucose concentration in the blood (hyperglycemia) (Gripp, Ennis and Napoli, 2013). WHO predicts an increase in the number of people with DM in Indonesia from 8.4 million in 2000 to around 21.3 million in 2030 (Soelistijo et al., 2015).

Diabetic neuropathy is a microvascular complication that often occurs with a prevalence of 30$50 \%$. The main contributing factors are hyperglycemia, and other factors such as age, duration, hypertension, increased triglyceride, increased BMI and alcohol consumption (Deli et al., 2013). Several mechanisms of diabetic neuropathy are known through vascular and metabolic pathways. Hyperglycemia can activate polyol pathways, advanced glycation end products (AGEs), hexosamine, protein kinase $\mathrm{C}$ (PKC), oxidative stress, nitrite oxide degeneration and inflammatory reactions. Activation of the complement pathway and formation of the membrane attack complex can damage blood vessels and affect circulation in the endoneurium. Homeostasis disorder causes a steady increase in the $\mathrm{Ca}^{2+}$ cytosol ion concentration, and a decrease in the amplitude of the $\mathrm{Ca}^{2+}$ ion depolarization induction signal. Besides the pathological role of calcium ions if the conditions are excessive will be a mediator for cell injury and death (Veves and Malik, 2007).

Hyperglycemic conditions increase in metabolic flux in the mitochondria, disruption of mitochondrial proton pump regulation so that the formation of ROS is increased. Reactive oxygen species are regulatory instruments for intracellular $\mathrm{Ca}^{2+}$ homeostasis and affect several other intracellular signaling pathways. Although ROS is highly controlled in blood vessels under physiological conditions, an increase in ROS during pathological conditions is a contribution to damage to blood vessels and the peripheral nervous system (El-Najjar et al., 2017). Cell lines are permanently formed cell cultures that will proliferate continuously if given medium and room temperature appropriate. It was said that cell lines play an important role in studying the pathophysiology, and the specific processes of cell differentiation (Pak, Son and Yoo, 2014).

Nimodipine is a type $\mathrm{L} \mathrm{Ca}^{2+}$ inhibitor that can reactivate the smooth muscle ATPase pathway such as blood vessels and also has a direct neuroprotective effect by reducing the entry of $\mathrm{Ca}^{2+}$ caused by intraaxial sodium accumulation, protecting and repairing endothelial cell dysfunction. It is also said that nimodipine can improve blood and nerve flow regulation in the pathogenesis of diabetic neuropathy and restore the adrenergic function of the vasa nervorum. Effects on blood flow neurons may be caused by local vasodilators because they have very little effect on the systemic (Kappelle et al., 1993).

\section{Materials and Methods}

\subsection{Research Design}

This study uses a pure experimental research design (true experimental design) at the Central Laboratory of Biological Sciences (LSIH) Universitas Brawijaya in vitro on neuron cell culture. 


\subsection{Research Samples}

The sample of this study used SH-SY5Y culture cells that met the inclusion and exclusion criteria, with a total sample of 20 . Samples were divided into 4 groups namely, given nimodipine $0.5 \mu \mathrm{M}$ $(\mathrm{n}=10)$ and without nimodipine $(\mathrm{n}=10)$.

\subsection{Calcium Intracellular Expression Examination}

Examination of $\mathrm{Ca}^{2+}$ intracellular expression using fluo-3 by immunoflorescence. $\mathrm{Ca}^{2+}$ intracellular observations were carried out using confocal laser screening microscopy (CLSM). $\mathrm{Ca} 2+$ intracellular calculation is done with Olympus Fluoview Ver4.2a with an au unit (aberrant unit).

\subsection{Reactive Oxygen Species (ROS) Expression Examination}

Examination of ROS expression using dichlorodihydrofluorescin diacetate (DCF-DA) by immunoflorescence. ROS observations were carried out using confocal laser screening microscopy (CLSM). ROS calculation is done with Olympus Fluoview Ver4.2a with an au unit (aberrant unit).

\section{Results}

Research on the effects of nimodipine on intracellular calcium and ROS expression in SH-SY5Y neuron cell cultures exposed to chronic hyperglycemia has been carried out. The first process is done through thawing cells and cell growth is done at least $80 \%$ confluent. Furthermore, after confluent subculture was carried out again and treated with $50 \mathrm{Mm}$ glucose concentration in the platting of 24 wells in which there was a coverslip, then incubated for 6 days. Subsequently given a 500nm nimodipine intervention for 30 minutes. After that, the intracellular calcium and ROS test labels in the SH-SY5Y neuron cell culture were examined using a confocal laser scanning microscopy (CLSM).

Observation of intracellular Calcium expression and ROS using a 400x magnification confocal microscope, each taken 6 random cell culture fields. Calcium expression before being observed was fixed and stained with fluo-3-immunostaining, whereas for ROS expression staining with H2DCFDA was first then fixed with $4 \%$ PFA.

One Way ANOVA statistical test for intracellular calcium mean in all four treatments $(\mathrm{p}<0.05)$ there were significant differences between $25 \mathrm{mM}$ glucose with $50 \mathrm{mM}$ glucose, $25 \mathrm{mM}$ glucose with $25 \mathrm{mM}$ glucose + nimodipine $0.5 \mu \mathrm{M}, 50 \mathrm{mM}$ glucose with $50 \mathrm{mM}$ glucose + nimodipine $0.5 \mu \mathrm{M}, 25 \mathrm{mM}$ glucose + nimodipine $0.5 \mu \mathrm{M}$ with glucose $50 \mathrm{mM}+$ nimodipine $0.5 \mu \mathrm{M}$ (table 1 ).

Table 1: Calcium intracellular mean result

\begin{tabular}{|l|c|c|}
\hline \multicolumn{1}{|c|}{ Treatment Group } & Mean \pm SD & p-value \\
\hline Glucose $25 \mathrm{mM}$ & $30.41 \pm 8.24^{\mathrm{a}}$ & \multirow{2}{*}{0.001} \\
\hline Glucose $50 \mathrm{mM}$ & $49.89 \pm 24.26^{\mathrm{b}}$ & \multirow{2}{*}{0.001} \\
\cline { 1 - 2 } Glucose $25 \mathrm{mM}+$ nimodipine $0.5 \mu \mathrm{M}$ & $45.32 \pm 31.12^{\mathrm{b}}$ & \\
\hline
\end{tabular}


\begin{tabular}{l|l|l} 
Glucose $50 \mathrm{mM}+$ nimodipine $0.5 \mu \mathrm{M}$ & $23.88 \pm 11.39^{\mathrm{a}}$
\end{tabular}

Note: $(a, b)$ different notations show meaningful differences.

Observation of ROS expression found significant differences $(\mathrm{p}<0.05)$ in the $25 \mathrm{mM}$ glucose treatment group with $50 \mathrm{mM}$ glucose, $25 \mathrm{mM}$ glucose with $50 \mathrm{mM}$ glucose + nimodipine $0.5 \mu \mathrm{M}$, $50 \mathrm{mM}$ glucose with $25 \mathrm{mM}$ glucose + nimodipine $0.5 \mu \mathrm{M}$, and $25 \mathrm{mM}$ glucose + nimodipine $0.5 \mu \mathrm{M}$ with $50 \mathrm{Mm}$ glucose + nimodipine $0.5 \mu \mathrm{M}$ (table 2 ).

Table 2: ROS mean result

\begin{tabular}{|l|c|c|}
\hline \multicolumn{1}{|c|}{ Treatment Group } & Mean \pm SD & p-value \\
\hline Glucose $25 \mathrm{mM}$ & $15736.00 \pm 9285.93^{\mathrm{a}}$ & \multirow{3}{*}{0.010} \\
\hline Glucose $50 \mathrm{mM}$ & $47856.14 \pm 7048.31^{\mathrm{b}}$ & \\
\cline { 1 - 2 } Glucose $25 \mathrm{mM}+$ nimodipine $0.5 \mu \mathrm{M}$ & $30091.57 \pm 28501.80^{\mathrm{a}}$ & \\
\hline Glucose $50 \mathrm{mM}+$ nimodipine $0.5 \mu \mathrm{M}$ & $63318.86 \pm 59207.13^{\mathrm{b}}$ & \\
\hline
\end{tabular}

Note: $(a, b)$ different notations show meaningful differences.

The correlation test used for the hyperglycemic group with nimodipine between intracellular calcium levels and ROS expression was the Spearman Rank correlation test. Obtained correlation coefficient ( $r$ ) of 0.500 indicates a positive correlation. The obtained $p$ value $>0.05$ which shows that in a state of hyperglycemia with the addition of 500nm nimodipine, an increase in intracellular calcium and ROS expression but did not have a significant correlation.

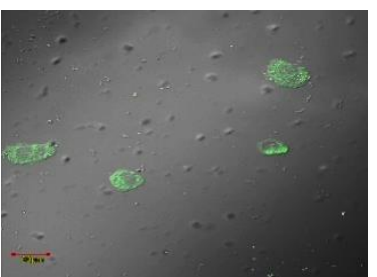

A

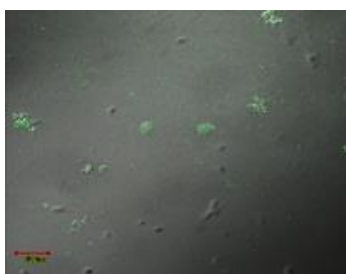

B

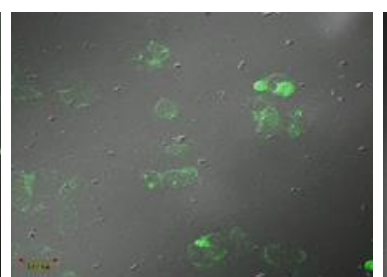

$\mathrm{C}$

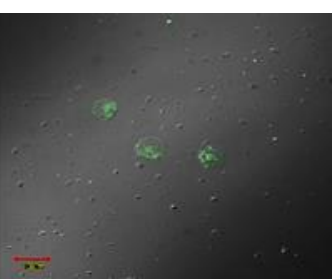

D

Figure 1: $\mathrm{Ca}^{2+}$ intracellular and ROS expression in neuron culture by treating hyperglycemia (50 $\mathrm{mM})$. Figures A (Calcium intracellular) and B (ROS) without the administration of nimodipine, C (Calcium intracellular) and D (ROS) are treated with $0.5 \mu \mathrm{M}$ nimodipine. (Culture day $6, \mathrm{Ca}^{2+}$ and ROS Fluorescent, DIC, superimpose, 400x magnification).

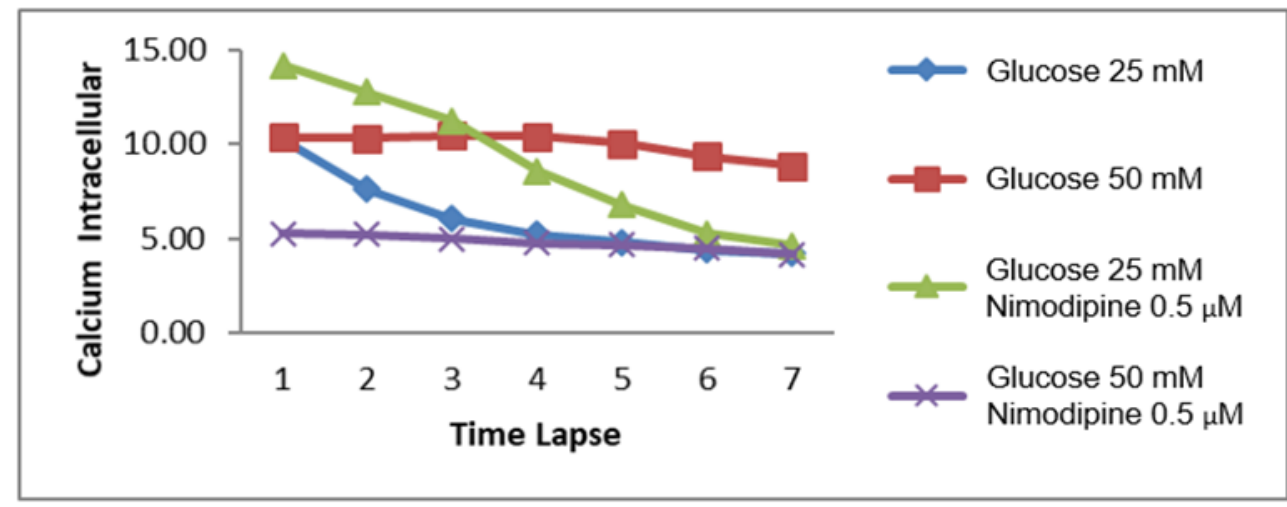

Figure 2: Average histogram of calcium intracellular expression in SH-SY5Y neuron culture with nimodipine $0.5 \mu \mathrm{M}$ intervention and without nimodipine. 


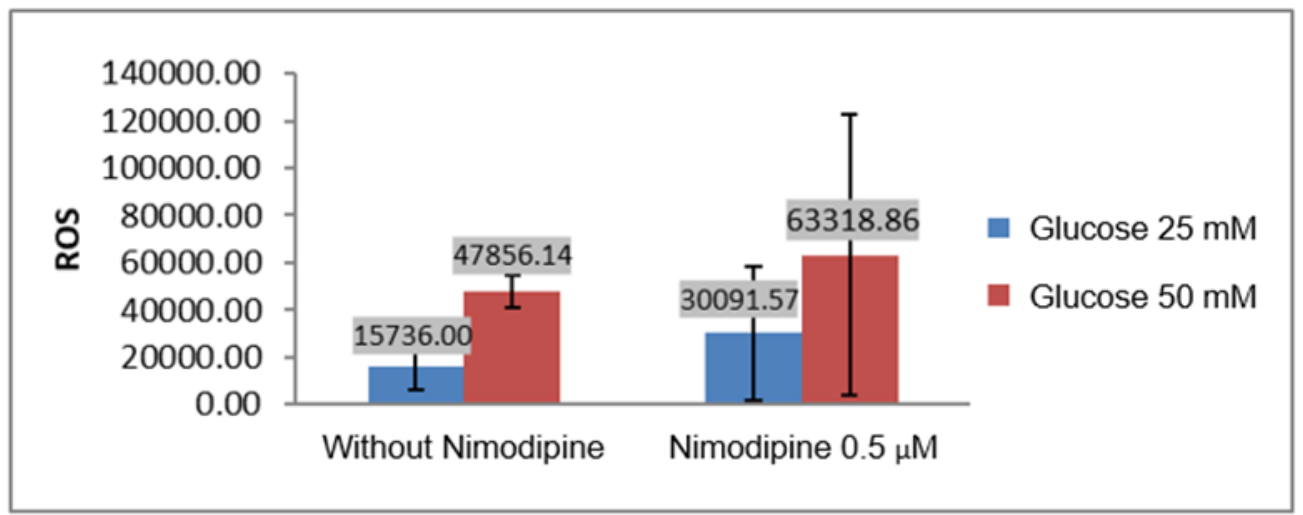

Figure 3: Average histogram of ROS expression in SH-SY5Y neuron culture with nimodipine $0.5 \mu \mathrm{M}$ intervention and without nimodipine

\section{Discussions}

Based on the results of the study $\mathrm{Ca}^{2+}$ expression in normoglycemic cells compared with hyperglycemia there were differences in the mean Ca2+ expression results (30.41 and 49.89). Cells that were exposed to hyperglycemia have higher intracellular $\mathrm{Ca}^{2+}$ levels compared to normoglycemia. This is in accordance with research conducted by Verkhratsky, 2008 that the provision of chronic glucose exposure could increase levels of intracellular $\mathrm{Ca}^{2+}$ neurons (Guerrero-Hernandez and Verkhratsky, 2014). $\mathrm{Ca}^{2+}$ cytosol concentrations were maintained at low levels of $50-100 \mathrm{nM}$ through active and passive mechanisms. There is close communication between the endoplasmic reticulum (ER) and mitochondria, because ER produces calcium regularly and cytotoxicity is always accompanied by an increase in cellular calcium from increased plasma calcium intake, intracellular storage, reduced calcium buffering and extrusion from several combinations of events above (El-Najjar et al., 2017). In this study, an increase in ROS expression in hyperglycemic state (15736.00 vs 47856.14) was in accordance with Chopra et al study, where intracellular ROS expression was significantly increased in SH-SY5Y cells exposed to chronic hyperglycemia for 6 days compared to normal cells. Hyperglycemic conditions cause an increase in metabolic flux and interference with proton pump regulation in the mitochondria so that the formation of ROS increases. Reactive oxygen species are regulatory instruments for intracellular $\mathrm{Ca}^{2+}$ homeostasis and affect several other intracellular signaling pathways. Although ROS is highly controlled in blood vessels under physiological conditions, an increase in ROS during pathological conditions is contributed to damage to blood vessels and the peripheral nervous system (El-Najjar et al., 2017).

Nimodipine is a type L calcium inhibitor that can reactivate the smooth muscle ATPase pathway of blood vessels and has a direct neuroprotective effect by reducing the entry of calcium caused by intraaxonal sodium accumulation, protecting and improving endothelial dysfunction (Kappelle et al., 1993). In this study the use of $0.5 \mu \mathrm{M}$ nimodipine in cell culture in a hyperglycemic state could significantly reduce intracellular calcium expression $(\mathrm{p}<0.05)$. This is in accordance with Kappelle research 1994, that the administration of nimodipine could restore a response that decreases independently in the post-collapse and increase the adrenergic response especially at the prespecified level. The adrenergic responsiveness of the sciatic nerve is investigated as a parameter for autonomic neuropathy. As for the expression of ROS in this study in a state of hyperglycemia 
by administering nimodipine $0.5 \mu \mathrm{M}$, there was still an increase or no significant difference ( $p>0.05$ ). This is in contrast to Singh 2016's study, which states that a dose of nimodipine 0.1$10 \mu \mathrm{M}$ significantly weakens the loss of 1-methyl-4-phenyl pyridinium ion induced by mitochondria, membrane potential and increased intracellular calcium levels in the cell line SHSY5Y (Singh et al., 2016). In line with the 2014 Herzfeld study, that the dose of nimodipine $1,10.20 \mu \mathrm{M}$ significantly decreased the cytotoxic cells induced by EtOH $62 \%$ (Herzfeld et al., 2014). The correlation test of intracellular calcium expression and ROS in 50mM glucose-induced cell culture by administering $0.5 \mu \mathrm{M}$ nimodipine obtained $\mathrm{r}=0.50$ showed a positive correlation and $\mathrm{p}>0.05$. This shows that there is a relationship between intracellular calcium expression levels and ROS in hyperglycemic conditions with the addition of nimodipine, but not statistically significant.

\section{Conclusions}

Based on the results of research on the effect of $0.5 \mu \mathrm{M}$ nimodipine administration on intracellular calcium and ROS expression in SH-SY5Y neuron cell culture induced by chronic hyperglycemia (glucose $50 \mathrm{mM}$ ), it can be determined that the administration of $0.5 \mu \mathrm{M}$ nimodipine significantly decreases intracellular calcium expression, but has not been able to reduce ROS expression in chronic 50mM glucose, it can be concluded that administration of $0.5 \mu \mathrm{M}$ nimodipine significantly decreases intracellular calcium expression, but has not been able to reduce ROS expression.

\section{Acknowledgement}

This research was carried out with the financial support of BPPM (Agency for Research and Community Service) Faculty of Medicine, Brawijaya University, Malang, Indonesia.

\section{References}

[1] Deli,G., Bosnyak E., Pusch E., Komoly S., Feher G. Diabetic neuropathies: Diagnosis and management, Neuroendocrinology, 2013, 98(4), 267-280.

[2] El-Najjar, N., Kulkarni R., Nader N., Hodeify R., Machaca K. Effects of Hyperglycemia on Vascular Smooth Muscle Ca2+ Signaling, BioMed Research International, 2017.

[3] Gripp, K. W., Ennis, S. and Napoli, J. Exome Analysis in Clinical Practice: Expanding the Phenotype of Bartsocas-Papas Syndrome, American Journal of Medical Genetics, Part A, 2013, $1058-1063$.

[4] Guerrero-Hernandez, A. and Verkhratsky, A. Calcium signalling in diabetes, Cell Calcium. Elsevier Ltd, 2014, 56(5), 297-301.

[5] Herzfeld, E., Strauss C., Simmermacher S., Bork K., Horstkorte R., Dehghani F., Scheller C. Investigation of the neuroprotective impact of nimodipine on Neuro2a cells by means of a surgerylike stress model, International Journal of Molecular Sciences, 2014, 15(10), 18453-18465.

[6] Kappelle, A. C., Biessels G.J., Buren T.V., Erkelens D.W., De Wildt D.J. Effects of nimodipine on sciatic nerve blood flow and vasa nervorum responsiveness in the diabetic rat, European Journal of Pharmacology, 1993, 250(1), 43-49.

[7] Pak, E. J., Son, G. D. and Yoo, B. S. Cadmium inhibits neurite outgrowth in differentiating human SH-SY5Y neuroblastoma cells, International Journal of Toxicology, 2014, 33(5), 412-418.

[8] Singh, A., Verma, P., Balaji G., Samantary S., Mohanakumar K.P. Nimodipine, an L-type calcium channel blocker attenuates mitochondrial dysfunctions to protect against 1-methyl-4-phenyl1,2,3,6-tetrahydropyridine-induced Parkinsonism in mice, Neurochemistry International. Elsevier Ltd, 2016, 99, 221-232. 
[9] Soelistijo, S. A. et al. Konsensus Pengendalian dan Pencegahan Diabetes Melitus Tipe 2 di Indonesia, Perkeni, 2015.

[10] Veves, A. and Malik, R. A. Diabetic Neuropathy Clinical Management. Second edi. Edited by R. A. M. Aristides Veves. Manchester, UK, 2007.

[11] Kawano, T. Current Overview of Diabetic Neuropathy-Mechanisms, Symptoms, Diagnosis and Treatment. 2014, 89-105.

[12] Walton, E. L. Oxidative stress and Diabetes; Glucose response in the ROS. Biomedical Journal. Elsevier Ltd, 2017, 4(5), 241-244.

*Corresponding author.

E-mail address shahdevinandar@ub.ac.id 